\title{
Energy efficiency analysis of outdoor standalone photovoltaic-powered photobioreactors coproducing lipid-rich algal biomass and electricity
}

\author{
Emeka G. Nwoba ${ }^{\mathrm{a}}$, David A. Parlevliet ${ }^{\mathrm{a}, *}$, Damian W. Laird ${ }^{\mathrm{b}}$, Kamal Alameh ${ }^{\mathrm{c}}$, Julien Louveau ${ }^{\mathrm{d}}$, \\ Jeremy Pruvost ${ }^{\mathrm{d}}$, Navid R. Moheimani ${ }^{\mathrm{e}, \mathrm{f}}$ \\ ${ }^{a}$ Engineering and Energy, Murdoch University, Western Australia 6150, Australia \\ ${ }^{\mathrm{b}}$ Chemistry and Physics, Murdoch University, Western Australia 6150, Australia \\ ${ }^{\mathrm{c}}$ Centre of Excellence for MicroPhotonic Systems, Electron Science Research Institute, Edith Cowan University, Joondalup, Western Australia 6027, Australia \\ ${ }^{\mathrm{d}}$ Université de Nantes, Oniris, CNRS, GEPEA, UMR 6144, F-44600 Saint-Nazaire, France \\ e Algae R\&D Centre, Environmental and Conservation Sciences, Murdoch University, Western Australia 6150, Australia \\ ${ }^{\mathrm{f}}$ Centre for Sustainable Aquatic Ecosystems, Harry Butler Institute, Murdoch University, Western Australia 6150, Australia
}

\section{H I G H L I G H T S}

- 1-ha microalgal plant based on novel photobioreactor design has NER of 3.0.

- Integrated PV module produces energy excess to requirements for plant operation.

- NER for novel photobioreactor comparable to agricultural biofuel crops.

- Spectral selection and PV technologies result in standalone operation.

- Novel photobioreactor offers energy and water sustainable production of microalgae.

\section{A R T I C L E I N F O}

\section{Keywords:}

Biofuel

Cooling

Nannochloropsis

Net energy ratio

Photovoltaic electricity

Spectrally-selective photobioreactor

\begin{abstract}
A B S T R A C T
The need for thermal regulation in microalgal photobioreactors is a significant impediment to their large-scale adoption. The energy costs associated with thermal regulation alone can easily result in a negative energy balance. Self-sustaining photovoltaic powered photobioreactors that do not require cooling systems provide an opportunity to maximize biomass productivity, generate local electricity, reduce thermal regulation requirements, and significantly improve the energy balance of the system. Net energy analysis of a spectrally-selective, insulated-glazed photovoltaic photobioreactor (IGP) with an integrated capability for renewable electricity generation used to cultivate Nannochloropsis sp. without freshwater-based cooling resulted in a net energy ratio of 2.96, a figure comparable to agricultural bio-oil crops such as Jatropha and soybean. Experimental data from pilot-scale operation of this novel photobioreactor producing Nannochloropsis biomass under outdoor conditions was extrapolated to a 1-ha IGP installation. Annual biomass productivity reached 66.0-tons dry weight ha ${ }^{-1}$, equivalent to overall energy output of $1696.2 \mathrm{GJ} \mathrm{ha}^{-1}$. The integrated semi-transparent photovoltaic panels generated an additional $1126.8 \mathrm{GJ} \mathrm{ha}^{-1} \mathrm{yr}^{-1}$ (313.0 $\mathrm{MWh} \mathrm{ha}^{-1} \mathrm{yr}^{-1}$ ). Energy demands from plant building materials, machinery, fertilizers, plant operations, and biomass harvesting constituted total energy input with a combined value of $707.3 \mathrm{GJ} \mathrm{ha}^{-1} \mathrm{yr}^{-1}$. Comparison with a conventional photobioreactor requiring passive evaporative cooling showed novel photobioreactor had a 73\% greater net energy ratio. Nannochloropsis cultivation in IGP system ensured co-production of lipid and protein of 34.7 and 25.7-tons ha $^{-1} \mathrm{yr}^{-1}$, respectively. These results suggest that this novel photobioreactor could be a viable and sustainable biomass production technology for mass microalgal cultivation.
\end{abstract}

\section{Introduction}

Microalgae represent an efficient solar-driven biotechnology resource for the environmentally sustainable production of biofuels, food, feed, cosmetics, fine chemicals, fertilizers, and biopharmaceuticals. The basis of the promise of microalgae as a biorenewable 
resource, include: (a) high lipid yields (up to $60 \mathrm{~m}^{3} \mathrm{ha}^{-1}$ vs. $2 \mathrm{~m}^{3} \mathrm{ha}^{-1}$ for Jatropha, or $0.2 \mathrm{~m}^{3} \mathrm{ha}^{-1}$ for corn [1]); (b) high conversion of solar energy to product (theoretical maximum values of $10 \%$ for microalgae vs. $6 \%$ for C4 plants [2]); (c) rapid reproduction cycles allowing for semi-continuous or continuous harvesting; (d) potential for $\mathrm{CO}_{2}$ sequestration (1 kg biomass is equivalent to $1.8 \mathrm{~kg} \mathrm{CO}_{2}$, [3]); (e) no requirement for high-value agricultural land, reducing competition with food-based crops; and (f) flexible inputs for culture systems including sea-/industrial, domestic and agricultural waste-water, flue gas, thus avoiding freshwater dependence $[4,5]$ and valorize waste streams [6-9].

This combination of features has led many to view microalgal production as a panacea to the environmentally sustainable production of many bio-based products, rather than current efforts using agricultural plant-based systems. However, microalgal culture requires far greater energy input than the production of traditional terrestrial crops. For example, in their study of the environmental impact of oil production in Italy, Jez et al. [10] reported that oil production from microalgae still has greater negative environmental impacts compared to traditional crops (e.g., sunflower and rapeseed) due to excessive energy demand and input material consumption. The cultivation of microalgae, in addition to harvesting of biomass, was by far, the biggest contributor (60.9\%) to the electrical energy needs and environmental impact [10]. The authors did note that the environmental impact of algal production could be reduced considerably by the use of renewable, specifically solar energy to provide the electricity to drive cultivation. Recently, Morales et al. [11] have indicated that there is a balance to be achieved between environmental impacts and energy when integrating photovoltaic panels with microalgal cultivation. Thus, to effectively exploit microalgae as a renewable bioresource, the energy efficiency of cultivation systems need to be considerably improved for commercial-scale production.

The two conventional systems for the commercial production of microalgae are open pond systems and closed photobioreactors [12]. Open ponds (e.g., classical raceways) are attractive commercially due to their low capital investment costs and are considered the cheapest technology for mass microalgal production $[13,14]$. However, low biomass productivity and the inability to sustain year-round production due to a high rate of culture contamination are significant limitations associated with open ponds $[1,13,15]$. Closed photobioreactors can offer optimal biophysiological conditions that lead to higher biomass productivity with a lower tendency for contamination. Unfortunately, photobioreactors are prone to overheating under outdoor conditions, which results in lower productivity and high cell mortality. As such, temperature and thermoregulation of cultures in photobioreactors is a well-recognized problem in solar microalgal farming [16]. This can also contribute to high environmental and energy costs in those temperate areas of the world where the solar resource is ideal for microalgal culture, e.g., western USA, Israel, north-western Australia.

Under outdoor conditions, $>50 \%$ of the solar radiation hitting the photobioreactor surface is within the infrared region (i.e., wavelengths above $700 \mathrm{~nm}$ ) and directly contributes to overheating the culture [17]. Consequently, up to $95 \%$ of collected solar spectral energy is transformed to heat by the culture [18]. Microalgae have optimal temperature windows, in which maximum bioproductivity is achieved. In summer (especially in the tropics), supra-optimal (high) temperatures that are lethal to microalgae are easily reached in closed photobioreactors necessitating the use of cooling systems. In contrast, suboptimal (low) temperatures occur in temperate regions, especially during winter, and these can lead to deterioration in growth and loss of productivity, making it necessary to heat cultures [19]. Year-round productivity in photobioreactors can then really only be achieved by cooling and heating photobioreactors and this is enough to lead to a negative energy balance of the system, even before considering other inputs such as materials, mechanical operations, and required nutrients. Therefore, effective temperature control of algal solar photobioreactors is a serious challenge to the overarching goal of cost-effective, environmentally sustainable, low-energy consuming microalgal production.

The problem of photobioreactor temperature control lends itself to novel approaches for the design of photobioreactors that are selfcooling (and require no heating in winter) and integrate photovoltaic electricity generation. These could then be optimized for maximal biomass productivity over the year to significantly decrease energy demand and address the negative net energy balance of algal photobioreactors. To this end, Moheimani and Parlevliet [20] proposed a microalgae production plant utilizing semi-transparent, spectrally-selective photovoltaic (PV) filters positioned above the culture facilities. This system could transmit a specific light spectral range to the culture while capturing and redirecting the remaining wavelengths to the PV cells for electrical energy generation. This idea paved the way for the design and development of an energy-harvesting spectrally-selective insulated glazed photovoltaic (IGP) photobioreactor [21,22]. The IGP photobioreactor has a transparent (thin-film, CdTe) PV panel $(40 \%$ transmission) and a low-emissivity (low-e) film [21]. The PV panel is glued to the upper part of the reactor to generate electrical power for production operations, removing the requirement for grid electricity. The low-e film is embedded in the illumination surface and selectively allows $>70 \%$ of photosynthetically-beneficial wavelengths from sunlight to reach the microalgae culture, while simultaneously reflecting $>90 \%$ of ultraviolet and infrared radiation [21]. Filtering out the non-photosynthetic wavelengths (e.g., above $700 \mathrm{~nm}$ ), should keep the temperature in the photobioreactor below the upper critical limit without the need for freshwater-related cooling during the day [22]. In the same vein, the large temperature drops at night typical of conventional photobioreactors can also be mitigated by the insulated panels, ensuring a culture temperature above the lower critical limit for most microalgae species. Although on the surface this solution sounds attractive, the actual energy balance of the technology needs to be rigorously assessed.

The net energy ratio (NER) is a standardized parameter used to evaluate the energetic productivity of a system [23] and represents a quantitative and scientific evaluation of the ratio between total energy production and primary non-renewable (fossil) energy requirements in the production process during a technology's life cycle [24,25]. An NER $\geq 1$ corresponds to the energy output exceeding the energy input, and such a system is obviously desirable [25-27]. Assessment of process sustainability for algal production systems (especially for biofuels) has been carried out mainly on systems based upon open ponds [23,28-32]. The energy balance of closed photobioreactors, and particularly flat panel reactors, have been subjected to far less scrutiny. The reported range of the calculated NER for these types of systems varies widely. For example, Jorquera et al. [23] used a GaBi program to produce values of 4.5 and 1.7 for production of biomass and oil, respectively, from Nannochloropsis sp grown in a flat panel photobioreactor, while another research focussed on Scenedesmus obliquus reported values between 0.39 and 7.81 when cultured at mid-temperate latitudes [33]. In the most comprehensive treatment of photobioreactor energy efficiency, Tredici et al. [34] recently reported an NER of 0.6 for biomass production in an industrial-scale Green Wall Panel photobioreactor system culturing Tetraselmis suecica in Italy and 1.7 for a similar siliconbased PV-integrated system located in Africa. The data from the limited number of studies on photobioreactors to date seem to indicate that overall NER is due to both photobioreactor design, the species being cultured and the location of the facility. In fact, Morales et al. [11] have indicated that there is a compromise that needs to be made between optimizing energy efficiency and environmental impact when assessing commercial microalgal production using photobioreactors.

Only a few studies have investigated the supply of energy to the system using PV, but none of those have explored the actual integration of PV panels into photobioreactors themselves. Combining spectral filtering technology and PV electricity generation into an individual 
photobioreactor module should mean that more modules can be placed per hectare as well as reducing heating and cooling costs to maintain the microalgal cultures at temperatures for maximum biomass productivity.

This study aims to evaluate the NER of a pilot-scale flat panel photobioreactor that incorporates self-cooling and integrated photovoltaic energy generation for cultivation of Nannochloropsis sp.; a microalga often touted as a potential biofuel feedstock. The result of the energy analysis of this novel photobioreactor is compared to a photobioreactor utilizing a passive evaporative cooling (PEC) using the same system boundaries. The strength of this analysis is the use of experimental biomass productivity and power efficiency data obtained from the operation of both types of photobioreactor. However, the authors emphasize that the validity of the conclusions is only applicable within the defined boundary limits and use of the IGP photobioreactor system.

\section{Materials and methods}

\subsection{Functional unit, system boundaries, and source of data}

For clarity and easy comparability, this energy balance analysis is carried out following the methodology of Tredici et al. [34], and utilizes similar system boundaries. The functional unit chosen for the current analysis is a 1-ha IGP photobioreactor plant. The choice of a 1-ha plant is not a reflection of the appropriate scale of an algae facility but a manageable size for industrial food or fuel-based applications of algae. It could be argued that a larger plant size would be needed to provide a realistic estimate of energetic efficiency for the production of biocommodities, but larger scales may vary the outcome of the analysis. The experimental data collected from the operation of a single pilotscale IGP photobioreactor was extrapolated to a 1-ha plant located in Western Australia.

The analysis begins with the cultivation and terminates with the production of a biomass paste containing 70-80\% (passing through centrifuge) moisture content. The boundary limits of the pathways for the production of biomass and downstream processing are contained in Fig. 1. The analysis was tailored to focus exclusively on the processes required for wet biomass production so as to remove the uncertainty associated with the choice of upstream and downstream processing possibilities. As the IGP unit is a standalone photobioreactor with a self-

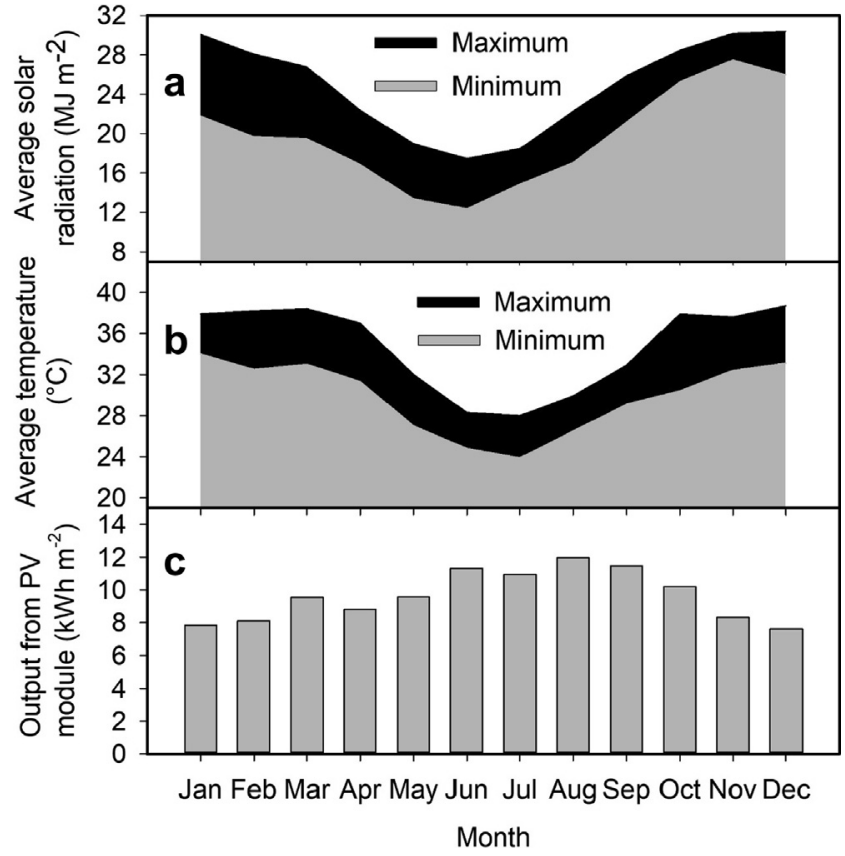

Fig. 2. (a) Monthly average of daily maximum and minimum solar radiation, (b) air temperature (www.bom.gov.au), and (c) photovoltaic panel output in Karratha from 1990 to 2018.

cooling mechanism, access to a freshwater source for cooling is not considered.

Site selection for large-scale microalgal production is largely determined by the topography, climate, weather conditions, land cost and availability, and the engineering of the cultivation systems [35-38]. Consequently, geospatial factors, such as temperature, solar radiation, water availability, rainfall pattern, and length of season, govern algal productivity. In this context, Karratha $\left(20^{\circ} 43^{\prime} 56.32^{\prime \prime} \mathrm{S}, 116^{\circ} 35^{\prime} 57.97^{\prime \prime}\right.$ E, elevation $5 \mathrm{~m}$ ) in Western Australia was chosen as a suitable area for locating the plant as it has previously been identified as a potential location for large-scale cultivation of microalgae [35] and is considered comparable to a number of similar temperate climate cultivation sites

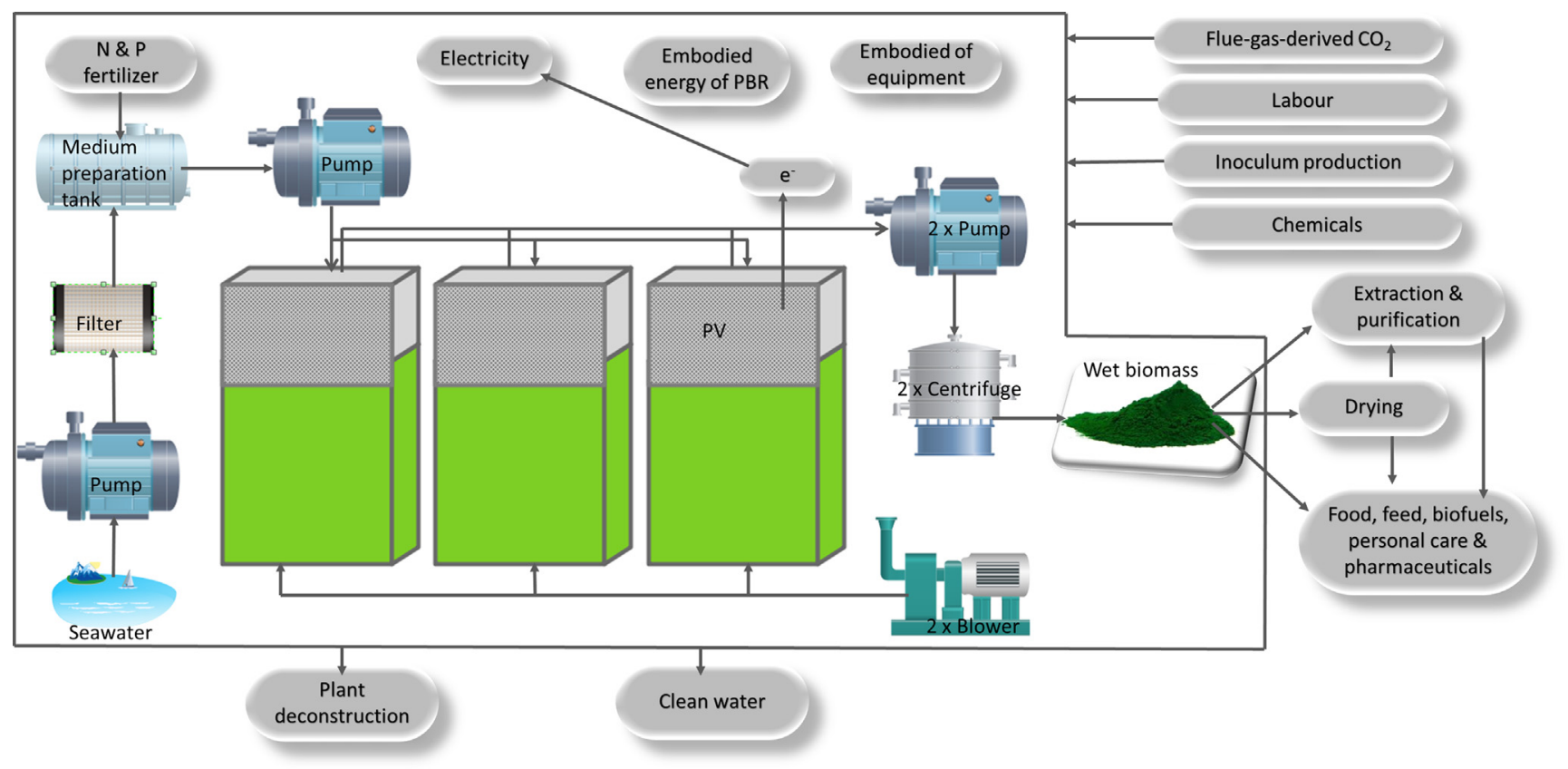

Fig. 1. A schematic of microalgal biomass production using a standalone IGP photobioreactor. The solid box shows system boundaries for the energy analysis. 
around the world. Further, Karratha is close to the sea (Euclidean distance between the plant and seawater intake of 1-1.5 km) ensuring availability of seawater for medium preparation, has high solar irradiance (16-28 $\mathrm{MJ} \mathrm{m}^{-2} \mathrm{yr}^{-1}$ and 7-9 sunlight hours per day), favorable climatic conditions (average temperature, $24-35^{\circ} \mathrm{C}$ ) (Fig. 2), proximity to industries for flue gas availability, a history as a trial site for largescale cultivation of microalgae [35], and the climatic conditions are known to support high biomass productivity over the course of a whole year (Emeritus Prof. Michael Borowitzka, pers. comm). Utilizing seawater for microalgae cultivation does not necessarily eliminate the requirement for freshwater, as that will be needed to compensate for evaporation losses and consequential increase in culture salinity. Energy and life-cycle analyses of microalgal culture typically include freshwater in their parameter set, usually because of the high evaporative losses from open pond systems. However, evaporative losses in photobioreactors are significantly lower; thus, freshwater resources have not been factored into the current study.

Energy output is defined as the summation of the chemical energy stored in the microalgal biomass and the surplus electrical energy produced by the PV modules per hectare per annum. Calculation of the energy input required to operate the plant was based on three main parameters as outlined by Tredici et al. [34], namely: (i) the embodied energy of materials; (ii) the energy of fertilizers, and; (iii) the energy required for operating pumps, centrifuges, and thermal regulation. The energy required for plant dismantling, and that provided by labor are excluded as their contribution to inputs have been shown to be marginal [34].

\subsection{Sizing and operation of 1-ha IGP photobioreactor plant}

The IGP unit used in the experiments is a customized flat panel photobioreactor constructed of insulated glass units (IGUs) with an integrated energy-generating photovoltaic (PV) panel (Fig. 3). It is comprised of five $5 \mathrm{~mm}$ thick IGUs, each having two glass panels sealed together with an airspace between them to ensure high thermal insulation properties. The solar facing $120 \mathrm{~cm} \times 150 \mathrm{~cm}$ (length $\times$ height) IGU has a low-emissivity (low-e) thin film deposited on the outer surface. The low-e film is spectrally-selective, allowing $>75 \%$ of visible light to pass through while blocking $>90 \%$ of the ultraviolet and infrared spectral components. This reduces heat loss in winter by reflecting the heat escaping the photobioreactor back into the culture and reduces heat gain during summer via spectral selection/ reduction, and avoids freshwater cooling. The rear and bottom IGUs of the photobioreactor do not contain the low-e film, but those on the sides do. A $120 \mathrm{~cm} \times 60 \mathrm{~cm}$ (length $\times$ height) semi-transparent solar glass CdTe PV panel was glued to the upper part of the external surface of the solar facing IGU. This allowed $40 \%$ of the incident sunlight through to the interior of the photobioreactor while converting the remainder to electricity, which is typically stored in a battery and used for providing electrical power for essential photobioreactor functions (e.g., air pump for mixing). The PV panel was placed $90 \mathrm{~cm}$ above the base of the IGP unit, to allow maximum solar harvesting. The plate reactor was inclined at a tilt angle of $32^{\circ}$, with a north-south orientation to maximize light capture [36]. The photobioreactor has an internal optical path length of $10 \mathrm{~cm}$ and an active culture volume of $140 \mathrm{~L}$. The microalgae suspension was mixed continuously by feeding filter-sterilized ambient air from both ends of $1.20 \mathrm{~m}$ long ceramic diffusers installed at the base of the photobioreactor. The airflow was provided by a PondOne O2 Plus 8000 air pump $\left(4200 \mathrm{~L} \mathrm{~h}^{-1}\right)$ at an aeration rate of $0.21 \mathrm{vvm}$ (volume of air per volume of culture per minute) and airflow pressure was regulated with a flowmeter. This aeration rate corresponds to a superficial gas velocity of $0.0039 \mathrm{~m} \mathrm{~s}^{-1}$, mixing time of $106.3 \pm 3.20 \mathrm{~s}$, and gas-hold of $0.017 \pm 0.0002$ in the photobioreactor under a biphasic system composed of air and tap water $[39,40]$. Culture $\mathrm{pH}$ was unregulated, and no $\mathrm{CO}_{2}$ gas was infused into the cultures.

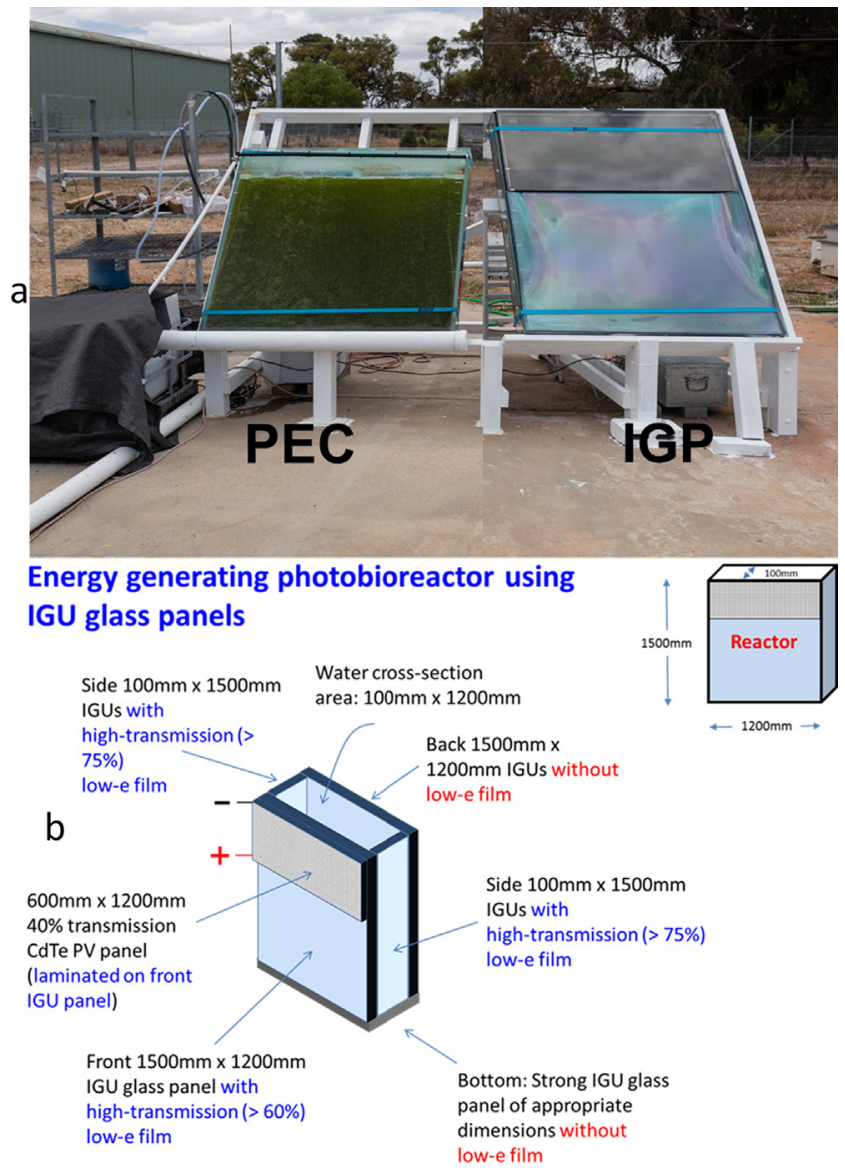

Fig. 3. (a) Insulated glazed photovoltaic (IGP) and passive evaporative cooling (PEC) photobioreactors operation at Algae R\&D Centre, Murdoch University, Western Australia and (b) schematic showing the construction details of the IGP photobioreactor.

It was calculated that a 1 -ha plant $(100 \mathrm{~m} \times 100 \mathrm{~m})$ would comprise a grid of 71 (row) $\times 40$ (column) IGP units based on measurements obtained during the operation of the pilot-scale photobioreactors at the Murdoch University Algae R\&D Centre in Perth. This configuration allows a reactor gap of $20 \mathrm{~cm}$ on the east-west axis and a gap of $100 \mathrm{~cm}$ between rows. Multiple solar angles, ease of access to modules and space for equipment installation were taken into account when arriving at the optimized configuration for a 1-ha installation. The configuration thus contains 2840 IGP units with a total culture volume of $398 \mathrm{~m}^{3}$ and a total IGP surface area of $5112 \mathrm{~m}^{2}$, equating to a total illuminated surface area for algal culture of $3646.6 \mathrm{~m}^{2}$ and total surface area for PV electricity production of $2044.8 \mathrm{~m}^{2}$. The ratios of photobioreactor surface area and illuminated surface area to the occupied land surface area are 0.51 and 0.36 , respectively.

This analysis considered ancillary equipment following the procedure of Tredici et al. [34] including: blowers $(\times 2)$ for culture aeration; centrifugal pumps $(\times 4)$ for culture transfer, circulation of seawater, medium preparation and distribution; and centrifuges $(\times 2)$ for biomass separation. The analysis incorporated both the embodied and operational costs of energy. A photobioreactor with the same optical depth, culture volume, hydrodynamic indices, and system boundaries without the photovoltaic and low-e adaptations but requiring a passive evaporative cooling (PEC, Fig. 3) system was utilized as a comparator to the IGP module.

\subsection{Microalgae, culture medium and cultivation conditions}

The marine Eustigmatophyte, Nannochloropsis sp. MUR 267, isolated 
from the Swan-Canning Estuary, Western Australia [41] was obtained from the Culture Collection of Algae at Murdoch University (Algae Research and Development Centre), Australia. This alga is a candidate for large-scale production of biofuel, aquaculture feed, and valuable biochemicals (e.g., $\omega-3$ fatty acids) because of its fast growth, tolerance to biotic pollution and high energy conversion efficiency $[42,43]$. The Nannochloropsis sp. was cultivated using unsterilized (but filtered, $50 \mu \mathrm{m}$ ) natural seawater (Hillary's Beach, Western Australia) enriched with sterilized F/2-Si nutrients [44]. The growth medium was maintained at the ambient salinity of seawater, $33 \% 0$ (parts per thousand) $\mathrm{NaCl}$. The Nannochloropsis sp. inoculum used for this study was obtained from a non-axenic unialgal culture maintained in the logarithmic growth phase in a $2 \mathrm{~m}^{2}$ outdoor raceway pond for more than 12 months. The experiment was carried out during the austral spring (from October to November) of 2018.

\subsection{Energy inputs to the 1-ha photobioreactor plants}

\subsubsection{Embodied energy of materials, machinery, and associated equipment}

By definition, embodied energy is the "total primary non-renewable energy consumed during the whole lifetime of a product" [45]. The embodied energy data used for this study was based on the information available in the literature [34,45-48]. Consideration was given only to the energy consumed during the extraction and processing of raw materials. Energy-related transportation costs and the recovery of materials post lifetime were excluded. The total embodied energy of a manufactured machine consists of the energy content of the materials that form the machine, the energy used for its production, and the maintenance energy [49]. Here, considerations are given to the energy content of the materials and that for machine production only. Lifetime information for machines and plant components are based on manufacturer's specifications and literature data [34]. Lifetime data for assembled machines are 5, 20, and 25 years for pumps, blowers, and centrifugal separators, respectively [34]. Quantity of materials required for the 1-ha plant construction was estimated based on manufacturer's data and pilot-scale operation of single IGP and PEC photobioreactors that were then extrapolated to 1-ha scale.

\subsubsection{Nitrogen and phosphorus fertilizers input, other nutrients and chemicals}

As seawater contains any necessary trace elements required for the growth of microalgae, this analysis considered only nitrogen $(\mathrm{N})$ and phosphorus $(\mathrm{P})$ supplied as sodium nitrate $\left(\mathrm{NaNO}_{3}\right)$ and sodium dihydrogen phosphate monohydrate $\left(\mathrm{NaH}_{2} \mathrm{PO}_{4} \mathrm{H}_{2} \mathrm{O}\right)$, respectively. The fertilizer input $\left(\mathrm{kg} \mathrm{ha}^{-1} \mathrm{yr}^{-1}\right.$ ) into biomass production was obtained from the areal biomass productivity $\left(\mathrm{g} \mathrm{m}^{-2} \mathrm{~d}^{-1}\right.$ or ton ha $\left.{ }^{-1} \mathrm{yr}^{-1}\right)$ based on an average biomass content of 6 and $0.6 \%$ for $\mathrm{N}$ and $\mathrm{P}$, respectively [50]. The fertilizer contribution to the total energy input was obtained from their yearly utilization and unit energy cost and expressed in $\mathrm{MJ} \mathrm{kg}^{-1}$.

\subsubsection{Primary energy input for operations}

The primary energy used by the electromechanical equipment is related to its total electrical energy production efficiency, which in turn varies with the fuel mix consumed for electricity production. In this analysis, the overall energy production efficiency is assumed to be $58 \%$ [34]. Electrical energy consumed by the equipment such as blowers, pumps, and centrifugal separators (for pumping operation, nutrient preparation, mixing, harvesting) was computed by multiplication of power requirements by working time for each machine.

Operations for medium preparation and culture harvesting comprise transfer of culture from the photobioreactors to the centrifugal separators and renewal of fresh growth medium in the reactors. An energy value of $0.058 \mathrm{kWh} \mathrm{m}^{-3}$ is assumed for the specific energy consumption required for culture pumping and medium preparation [34]. A harvesting ratio of $40 \%$ (159 of $398 \mathrm{~m}^{3}$ ) and harvesting frequency of three days, based on cell specific growth rate, are used. Given the proximity of the plant to seawater, the water required for medium renewal would be directly pumped from the sea, filtered and transferred to the growth medium preparation tank using a centrifugal pump. Energy for cooling of the IGPs is not considered as previous experimental results have indicated that the elimination of water-related cooling is possible using these IGP photobioreactors [22,42].

To prevent cells settling, achieve an optimal light/dark regime, and ensure adequate fluid transfer, the culture in the reactor is continuously mixed by way of air bubbling. The power consumption for mixing represents a significant proportion of the total primary energy input [34]. In this analysis, two blowers are considered to provide enough compressed air for mixing in a 1-ha plant. The energy consumed by the blowers is determined from Eq. (1) as described in Chisti [51] and further converted to electrical power by applying an electrical conversion yield of 0.58 [34].

$P_{w} / V_{l}=\rho_{l} g U_{w}$

where $\mathrm{P}_{w}=$ blower power input $(\mathrm{W}), \mathrm{V}_{l}=$ unit volume $\left(\mathrm{m}^{3}\right)$, $\rho_{l}=$ density of liquid $\left(\mathrm{kg} \mathrm{m}^{-3}\right), \mathrm{g}=$ acceleration due to gravity ( $\left.9.81 \mathrm{~m} \mathrm{~s}^{-2}\right)$, and $\mathrm{U}_{w}=$ superficial gas velocity $\left(\mathrm{m} \mathrm{s}^{-1}\right)$.

Considering the proximity of our chosen location to industrial sites in this analysis, $\mathrm{CO}_{2}$ supply will be sourced from flue gas in order to provide carbon and control the $\mathrm{pH}$ of the culture. Therefore, the electrical energy inputs for the supply of $\mathrm{CO}_{2}$-rich flue gas $\left(12.5 \% \mathrm{CO}_{2}\right)$ to blowers and inoculum production is assumed to be insignificant [34].

At every semi-continuous harvest (every three days of culture residence time), the culture is passed directly through a centrifuge without pre-concentration. In house experience suggests that the resulting biomass paste has a moisture content between $70 \%$ and $80 \%$. The specific power consumption of the centrifuge used for culture harvesting is considered to be $1.2 \mathrm{kWh} \mathrm{m}^{-3}$ [34].

\subsection{Energy output}

The energy output of the IGP plant was considered as the product of the ground areal biomass productivity $\left(\mathrm{g} \mathrm{m}^{-2} \mathrm{~d}^{-1}\right)$ and energy content of the biomass (GJ ha ${ }^{-1} \mathrm{yr}^{-1}$ ) plus the surplus energy produced by the PV panel (GJ ha $\mathrm{hr}^{-1}$ ) for a 1-ha site. The specific enthalpy of nutrient-replete Nannochloropsis sp. biomass grown in F/2-Si medium is considered to be $25.7 \mathrm{MJ} \mathrm{kg}^{-1}$ [50]. Based on available literature data for the chosen location [35], the annual cultivation period is restricted to the 11 sunniest months of the year (July to May) (Fig. 2). Given the experimental annual productivity data collected from microalgal plants previously operating in the chosen location, the average ground areal productivity for this cultivation period is around $28-30 \mathrm{~g} \mathrm{~m}^{-2} \mathrm{~d}^{-1}$ ([35], Emeritus Prof. Michael Borowitzka, pers. comm.). For this analysis, the average ground areal biomass productivity of the 1-ha IGP plant over a full year was conservatively estimated to be $20 \pm 5 \mathrm{~g} \mathrm{~m}^{-2}$ $\mathrm{d}^{-1}$. The data obtained from the basic energy measurement of the PV module was matched with the manufacturer's information sheet and used to simulate monthly average energy output for the chosen location (Fig. 2). Based on this calculation, the monthly average energy output from each individual module located at Karratha, Western Australia, is estimated to be $10.02 \pm 0.96 \mathrm{kWh}$. Therefore, the NER for the 1-ha IGP and PEC photobioreactors is calculated based on Eqs. (2) and (3), respectively.

Overall energy output (energy output from biomas

$N E R=\frac{s+\text { surplus energy output from PV) }}{\text { Total energy input (embodied energy }+ \text { energy for }}$ 
NER

$$
=\frac{\text { Energy output from biomass }}{\text { Embodied energy }+ \text { energy for operations }+ \text { energy for mixing }}
$$

\section{Results and discussion}

\subsection{Energy output}

The ground areal productivity achieved using the IGP photobioreactor at the Murdoch University Algae R\&D Centre in Perth during the austral spring (October-November 2018) was $16-23 \mathrm{~g} \mathrm{~m}^{-2} \mathrm{~d}^{-1}$, with no $\mathrm{CO}_{2}$ addition. Productivity could be increased by $70-80 \%$ with $\mathrm{CO}_{2}$ addition to the culture [52]. Notwithstanding this potential increase, a conservative figure of $20 \mathrm{~g} \mathrm{~m}^{-2} \mathrm{~d}^{-1}$ was chosen for the biomass productivity over the course of a year for this analysis. This level of productivity can be achieved for at least 11 months (330 days), corresponding to $66,000 \mathrm{~kg} \mathrm{ha}^{-1} \mathrm{yr}^{-1}$ (66.0 tons ha ${ }^{-1} \mathrm{yr}^{-1}$ ) of dry algal biomass and results in energy output of $1696.2 \mathrm{GJ}^{-1} \mathrm{yr}^{-1}$ based on a biomass energy content of $0.0257 \mathrm{GJ} \mathrm{kg}^{-1}$. Using an average of five "peak-sun" hours per day and 330 sunny days per year, the PV panels on the 2840 units produce a total electrical energy output of 313 MWh ha ${ }^{-1} \mathrm{yr}^{-1}$ (67 $\mathrm{W} \mathrm{m}^{-2}$ per panel), i.e., $1126.9 \mathrm{GJ} \mathrm{ha}^{-1} \mathrm{yr}^{-1}$. Hence, the overall energy output of the 1-ha IGP plant is 2823.1 GJ $\mathrm{ha}^{-1} \mathrm{yr}^{-1}$, with the PV integration contributing $40 \%$ of the total energy generated.

\subsection{Analysis of energy inputs}

\subsubsection{Embodied energy of photobioreactor, piping, and machinery}

The energy embodied in the materials required to build the 1-ha IGP plant is calculated to be $393.8 \mathrm{GJ} \mathrm{ha}^{-1} \mathrm{yr}^{-1}$ (Table 1). Therefore, the total embodied energy of the IGP photobioreactor, piping, fittings and machines adds up to $411.0 \mathrm{GJ} \mathrm{ha}^{-1} \mathrm{yr}^{-1}$. The major energy cost comes from the building materials for the IGP reactors, representing approx. $96 \%$ of the annualized energy input. The relative contributions of the energy embodied in fittings, piping, and ancillary equipment is almost negligible. This figure is similar to that reported by Tredici et al. [34], who found that $95 \%$ of the overall embodied energy required was due to the energy cost of the materials used to build a 1-ha Green Wall Panel (GWP) plant made of disposable low-density polyethylene film.

\subsubsection{Energy consumption for fertilizers and plant operations}

Consideration is only given to the nutrients, $\mathrm{N}$ and $\mathrm{P}$ fertilizer supplied as $\mathrm{NaNO}_{3}$ and $\mathrm{NaH}_{2} \mathrm{PO}_{4} \cdot \mathrm{H}_{2} \mathrm{O}$, for the $\mathrm{F} / 2-\mathrm{Si}$ medium [44]. The other major components of the $\mathrm{F} / 2$ medium recipe, including trace metals, are derived from seawater. Based on our decades of outdoor growth of Nannochloropsis sp., omitting specific trace element additions to seawater-based medium has a negligible effect on biomass productivity $[22,42,53]$. The energy consumption for the production of $\mathrm{N}$ and $\mathrm{P}$ fertilizers required to grow 66.0 tons $\mathrm{ha}^{-1} \mathrm{yr}^{-1}$ of Nannochloropsis sp. MUR 267 biomass is calculated to be $240.8 \mathrm{GJ} \mathrm{ha}^{-1} \mathrm{yr}^{-1}$ (Table 2). Using a culture residence time of three days, nutrient utilization efficiency is known to be $100 \%$ [22]. Therefore, post centrifuge water, that is effectively free of biomass, is clean and nutrient-free and fit for disposal without further treatment.

An airflow rate of $0.21 \mathrm{vvm}$ was maintained in the photobioreactor and found to be suitable for providing mixing throughout the experimental period [22]. The calculated power consumption for blowers was $38 \mathrm{~W} \mathrm{~m}^{-3}$, which amounts to a yearly electrical energy cost of $430.9 \mathrm{GJ}$ $\mathrm{ha}^{-1} \mathrm{yr}^{-1}$ (Table 3). This cost represents $83 \%$ of the total costs for plant operation and is the major contributor to the primary energy input (Table 3). The power consumption for culture harvesting using centrifuges is estimated at $1.2 \mathrm{kWh} \mathrm{m}^{-3} \mathrm{~d}^{-1}$, equating to electrical energy consumption by the centrifugal separators of $75.5 \mathrm{GJ} \mathrm{ha}^{-1} \mathrm{yr}^{-1}$, a value that represents $15 \%$ of the total operational costs and makes this the second-highest contributor to the primary energy input.

Total electrical energy consumption for plant operations was calculated to be $581.7 \mathrm{kWh} \mathrm{d}^{-1}$ or $517.3 \mathrm{GJ} \mathrm{ha}^{-1} \mathrm{yr}^{-1}$. At a $58 \%$ conversion efficiency, this operational energy consumption corresponds to $891.9 \mathrm{GJ} \mathrm{ha}^{-1} \mathrm{yr}^{-1}$ of primary energy input required.

\subsection{Energy balance (net energy ratio) of the 1-ha plant}

Calculation of the net energy ratio (NER) for any energy generating system entails a judgment on what constitutes the system boundaries. We have chosen to use previously established and validated system boundaries [34] (Fig. 1) in order to facilitate meaningful comparison between our results for the novel IGP design and those analyses already present in the open literature.

Using these system boundaries, a calculated NER value of 2.96 (Table 4) was found for the model 1-ha IGP plant with an annual output of 66.0 tons $\mathrm{ha}^{-1} \mathrm{yr}^{-1}$ of Nannochloropsis sp. biomass. This value implies that the sum of the photosynthetically-based chemical energy derived from the algal biomass and electrical energy produced by the photovoltaic panels is $66 \%$ higher than the non-renewable fossil fuel

Table 1

\begin{tabular}{|c|c|c|c|c|c|}
\hline Materials & $\begin{array}{l}\text { Embodied energy of } \\
\text { material }\left(\mathrm{MJ} \mathrm{kg}^{-1}\right)\end{array}$ & $\begin{array}{l}\text { Quantity of materials } \\
\text { required (tons } \text { ha }^{-1} \text { ) }\end{array}$ & $\begin{array}{l}\text { Lifetime of } \\
\text { material (years) }\end{array}$ & $\begin{array}{l}\text { Annual embodied energy } \\
\text { required (GJ ha-1 } \mathrm{yr}^{-1} \text { ) }\end{array}$ & $\begin{array}{l}\text { Percentage contribution to } \\
\text { embodied energy cost (\%) }\end{array}$ \\
\hline Glass (toughened) & $23.5^{\mathrm{a}}$ & 140.3 & $20^{\mathrm{b}}$ & 164.9 & $40.1(50.0)$ \\
\hline $\begin{array}{l}\text { Stainless steel for PBR framework } \\
\text { and fittings }\end{array}$ & $15.3^{\mathrm{b} *}$ & $130.0\left(\begin{array}{lll}1 & 4 & 0\end{array}\right)$ & $20^{\mathrm{b}}$ & $99.5(107.1)$ & $24.2(32.5)$ \\
\hline CdTe PV panel & $72^{\mathrm{a}}$ & 36.9 & $25^{\mathrm{b}}$ & 106.3 & 25.9 \\
\hline $\begin{array}{l}\text { PVC pipes and fittings for } \\
\text { aeration }\end{array}$ & $52.6^{\mathrm{a} *}$ & $2.2(2.8)$ & $5^{\mathrm{b}}$ & $23.1(29.5)$ & $5.6(8.9)$ \\
\hline IGP PBR & & & & $393.8(301.5)$ & $95.8(91.4)$ \\
\hline PVC for general piping & $52.6^{\mathrm{a} *}$ & $1.3(2.8)$ & $9^{c}$ & $7.6(16.4)$ & $1.8(5.0)$ \\
\hline Centrifuges & $56.7^{\mathrm{b}}$ & 2.0 & $25^{\mathrm{b}}$ & 4.5 & $1.1(1.4)$ \\
\hline Blowers & $56.7^{\mathrm{b}}$ & 1.0 & $20^{\mathrm{b}}$ & 2.8 & $0.7(0.8)$ \\
\hline Pumps & $56.7^{\mathrm{b}}$ & $0.2(0.4)$ & $5^{\mathrm{b}}$ & $2.3(4.5)$ & $0.6(1.4)$ \\
\hline Machines & & & & $9.6(11.8)$ & $2.4(3.6)$ \\
\hline Total embodied energy & & & & $411.0(329.7)$ & 100 \\
\hline
\end{tabular}

Embodied energy of materials for the building of a 1-ha IGP plant.

Values in parenthesis represent the results for PEC photobioreactor.

a [48]
b [34]
c [24]

* Energy content values for recycled materials used in the calculations 


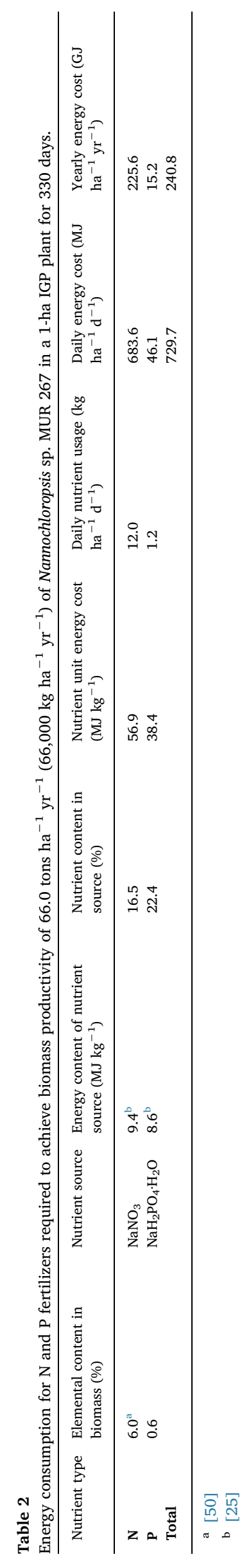

input required for the development and operation of the plant. This high NER is possible because the IGP system can be operated at nearmaximum productivity without additional thermal regulation and because the PV module provides all of the electrical energy required for plant operation (Table 4).

The results show that electrical energy consumption for culturing and harvesting (plant operations) corresponds to $56 \%$ of the primary energy input. The embodied energy of the plant materials and the fertilizers required for the growth of the microalgae represent $25 \%$ and $19 \%$, respectively, of the overall energy consumption. In the previous energy analysis by Tredici et al. [34] with the same system boundaries and plant size, energy for reactor operation represented the dominant primary energy input ( $59 \%$ of the total) to the plant. However, the value of the NER obtained in this study is $49 \%$ superior to the 1.7 reported for a hypothetical 1-ha PV-GWP-II integrated system for the production of Tetraselmis suecica biomass in Mediterranean African countries, such as Tunisia.

The study by Tredici and colleagues assumed that a $25 \%$ coverage of the GWP panels with Si-PV panels (15\% efficiency) was enough to produce all the electrical energy needed for production operations without decreasing the annual biomass productivity. Similarly, Sforza et al. [54] have proposed the use of a photovoltaic-driven photobioreactor and demonstrated that $30 \%$ coverage of the photobioreactor's illuminated surface with a conventional Si-PV panel does not result in a reduction in productivity. In other work, Barbera et al. [55] showed that 50\% coverage with Si-PV modules of the south-oriented roof for an east-west oriented PV-integrated greenhouse with open raceway ponds did not negatively affect biomass productivity. In our previous work with this novel photobioreactor, we have noted that although the integrated PV panel covers $40 \%$ of the total illumination surface, there is no decrease in the overall annual production of biomass [22]. What the current analysis shows is that the integration of the PV panel doesn't reduce achievable biomass productivity and actually produces a surplus energy output of approximately $235 \mathrm{GJ} \mathrm{ha}^{-1} \mathrm{yr}^{-1}$, a figure that represents $7 \%$ of total energy output from the IGP plant (Table 4). This additional electricity could be used to supply extra illumination and heat at night to increase productivity rates or used for biomass drying and other downstream processing, further improving the economic viability of large scale microalgal culture. Given that a previous report of a comparably sized flat plate photobioreactor producing Nannochloropsis sp. biomass determined an NER value of 4.5, the NER for the IGP looks relatively low [23]. However, the high NER value reported in that work is likely a result of a much less conservative estimate of annual biomass productivity (100 tons ha ${ }^{-1} c f .66$ tons ha ${ }^{-1}$ ), the exclusion of significant energy inputs such as nutrients, cooling and harvesting, and a disregard for energy losses due to the conversion of electricity input to primary energy. Those authors also assumed an energy content for the biomass of $30 \mathrm{MJ} \mathrm{kg}^{-1}\left(=3155 \mathrm{GJ} \mathrm{yr}^{-1}\right.$ ) which is only possible if the biomass has a lipid content at the higher end of expected lipid productivities available in the literature. Given that increase in lipid content of a culture is often associated with a reduction in biomass productivity, an output of 100 tons $\mathrm{ha}^{-1} \mathrm{yr}^{-1}$ of algal biomass under such conditions appears questionable. We believe that our more conservative lipid and biomass production values, which are derived from validated outdoor trials using the IGP photobioreactor technology and an analysis that includes realistic energy conversion losses and nutrient inputs provides a more realistic NER for production modelling.

\subsection{Comparison of NER of self-cooling PV-PBR (IGP) and freshwater- based passive evaporative cooling (PEC) photobioreactors}

The control of temperature in closed photobioreactors is a critical issue in solar microalgal farming and also has an impact on the energy consumption and environmental sustainability credentials of a commercial-scale operation. Passive evaporative cooling systems have 
Table 3

Power consumption for operation of the 1-ha IGP plant producing 66.0 tons ha $^{-1} \mathrm{yr}^{-1}$ of Nannochloropsis sp. biomass for 330 days.

\begin{tabular}{|c|c|c|c|c|c|}
\hline \multirow[t]{2}{*}{ Equipment } & \multirow[t]{2}{*}{ Function } & \multicolumn{2}{|c|}{ Power consumption } & \multirow{2}{*}{$\begin{array}{l}\text { Primary energy input } \\
-\left(\mathrm{GJ} \mathrm{ha}^{-1} \mathrm{yr}^{-1}\right)\end{array}$} & \multirow{2}{*}{$\begin{array}{l}\text { Contribution to operational } \\
\text { cost }(\%)\end{array}$} \\
\hline & & $\mathrm{kWh} \mathrm{d}^{-1}$ & $\begin{array}{l}\mathrm{GJ} \mathrm{ha}^{-1} \\
\mathrm{yr}^{-1}\end{array}$ & & \\
\hline $2 \times$ Centrifuge & Collection of algal biomasses & 190.8 & 75.5 & 130.2 & $14.6(8.8)$ \\
\hline $4 \times$ Pumps & $\begin{array}{l}\text { Seawater pumping for preparation of nutrient } \\
\text { medium, medium distribution and culture } \\
\text { pumping }\end{array}$ & 27.7 & 10.9 & 18.9 & $2.1(1.3)$ \\
\hline $2 \times$ Blowers & Mixing of culture & 363.0 & 430.9 & 742.9 & $83.3(50.7)$ \\
\hline $1 \times$ Submersible pump (PEC only) & Cooling & 280.8 & 333.3 & 574.7 & 39.2 \\
\hline Total & & $\begin{array}{l}581.5 \\
(862.3)\end{array}$ & $\begin{array}{l}517.3 \\
(850.6)\end{array}$ & $892.0(1466.7)$ & 100.0 \\
\hline
\end{tabular}

Values in parenthesis are percentage contribution for passive evaporative cooling (PEC) option.

commonly been used to maintain an optimum temperature for maximum biomass production [36], but this mechanism of temperature control can be challenging and leads to unfavorable energy balances at large scale. Being able to 'tune down' the energy demand for the thermal regulation of a photobioreactor used in microalgal production could result in significant improvements to the economic and environmental performance of commercial-scale microalgal 'farms'. This scenario was the inspiration for the design of the IGP photobioreactor and the combination of the use of selective filtering of incoming solar radiation to remove infra-red heat-producing wavelengths and recent work has shown that incorporation of infra-red reflecting materials, such as low-e films, on illuminated surfaces can remove up to $90 \%$ of incoming heat-inducing wavelengths without a deleterious impact on cell viability $[17,22,36]$. Use of these technologies has been shown to remove the necessity for extraneous cooling systems in outdoor applications [22].

In order to determine if the IGP based photobioreactor is really an improvement on the use of a cheaper to build flat plate, glass only system, the NER of a flat-panel photobioreactor requiring passive evaporative cooling (PEC) for culture temperature control was determined using the same boundary conditions used for the analysis of the IGP technology. Results from previous studies on Nannochloropsis sp. MUR 267 indicates that maximum bioproductivity was achieved when culture temperature is maintained at $<30{ }^{\circ} \mathrm{C}$ [43]. Temperature and solar radiation data from our model location of Karratha (Fig. 2) indicated that cooling for $5.6 \mathrm{~h}$ per day for 7-8 months of the year would be required if using a traditional photobioreactor design. A submersible pump with a power consumption of $0.077 \mathrm{kWh} \mathrm{m}^{-3}$ and a lifespan of 5 years [34] was considered adequate for such a cooling operation resulting in a requirement of approximately $1000 \mathrm{~kg} \mathrm{~m}^{-2} \mathrm{yr}^{-1}$ of water for cooling. Due to changes in materials required to construct the photobioreactor itself, the calculated embodied energy of a 1-ha PEC plant actually decreases to $329.7 \mathrm{GJ} \mathrm{ha}^{-1} \mathrm{yr}^{-1}$ (Table 1), but the total operational energy consumption climbs $64 \%$ to $1466.7 \mathrm{GJ}^{-1} \mathrm{yr}^{-1}$ (Table 4). Using a 58\% energy conversion efficiency, the cooling cost alone reaches $574.7 \mathrm{GJ} \mathrm{ha}^{-1} \mathrm{yr}^{-1}$, representing $39.2 \%$ of total operational energy cost (Table 3). A similar finding has been reported by Tredici et al. [34]. The overall NER of the 1-ha PEC plant producing 66.0 tons of dry biomass annually is calculated to be 0.83 (Table 4). This value is $72 \%$ lower than that calculated for the IGP based plant and well below the minimal threshold considered necessary for the sustainable production of biofuel, food, or feed based on wet biomass production.

\subsection{Significance of the work}

Overheating and high energy input in photobioreactors impede their scalability for microalgae-based biorefinery. Evaporative cooling systems utilizing a freshwater spray on the photobioreactor illuminated surface are not cost-competitive or sustainable due to high energy and water demand, driving the energy balance of closed photobioreactors to a negative value. Recently, the integration of photovoltaic modules into microalgal photobioreactor plant design has been mooted as a way to improve the net energy ratio of the system by providing locally produced, non-fossil fuel derived energy to generate electrical energy as well as partial shading of photobioreactors to reduce biomass productivity reductions due to photoinhibition. This work has taken that idea to the next step by integrating both spectrally-selective low-e films (to reduce heat gain) and semi-transparent PV panels (to generate electricity) onto the illumination surface of the photobioreactor.

The NER value of 2.96 achieved in this study is at least comparable to, if not better than, that reported for the most efficient

Table 4

Net energy ratio for biomass production from Nannochloropsis sp. using the 1-ha plant operating for 330 days.

\begin{tabular}{|c|c|c|c|}
\hline Parameter & Unit & IGP & PEC \\
\hline Ground areal productivity & $\mathrm{g} \mathrm{m}^{-2} \mathrm{~d}^{-1}$ & 20.0 & 20.0 \\
\hline Biomass productivity & tons $\mathrm{ha}^{-1} \mathrm{yr}^{-1}$ & 66.0 & 66.0 \\
\hline Biomass energy content & $\mathrm{MJ} \mathrm{kg}-1$ & 25.7 & 25.7 \\
\hline Energy output of biomass & GJ ha ${ }^{-1} \mathrm{yr}^{-1}$ & 1696.2 & 1696.2 \\
\hline Energy output from PV & GJ ha ${ }^{-1} \mathrm{yr}^{-1}$ & 1126.8 & 0 \\
\hline Total energy for operations & GJ ha ${ }^{-1} \mathrm{yr}^{-1}$ & 892.0 & $1466.7^{\text {*** }}$ \\
\hline Excess energy from PV & GJ ha ${ }^{-1} \mathrm{yr}^{-1}$ & $234.8(1126.8-892.0)^{*}$ & 0 \\
\hline Energy consumption for fertilizer & GJ ha ${ }^{-1} \mathrm{yr}^{-1}$ & 240.8 & 240.8 \\
\hline Energy embodied in materials & GJ ha ${ }^{-1} \mathrm{yr}^{-1}$ & 411.0 & 329.7 \\
\hline Total energy output & GJ ha ${ }^{-1} \mathrm{yr}^{-1}$ & $1931.0(1696.2+234.8)$ & 1696.2 \\
\hline Total energy input & GJ ha ${ }^{-1} \mathrm{yr}^{-1}$ & 651.8 & 2037.2 \\
\hline Net energy ratio & - & 2.96 & 0.83 \\
\hline Net gain & GJ ha ${ }^{-1} \mathrm{yr}^{-1}$ & 1279.2 & -341.0 \\
\hline
\end{tabular}

* Scenario where the PV is used to offset all the electrical energy for plant operations.

** Additional submersible pump for pumping cooling water with the exclusion of energy contained in water lost by evaporation. 


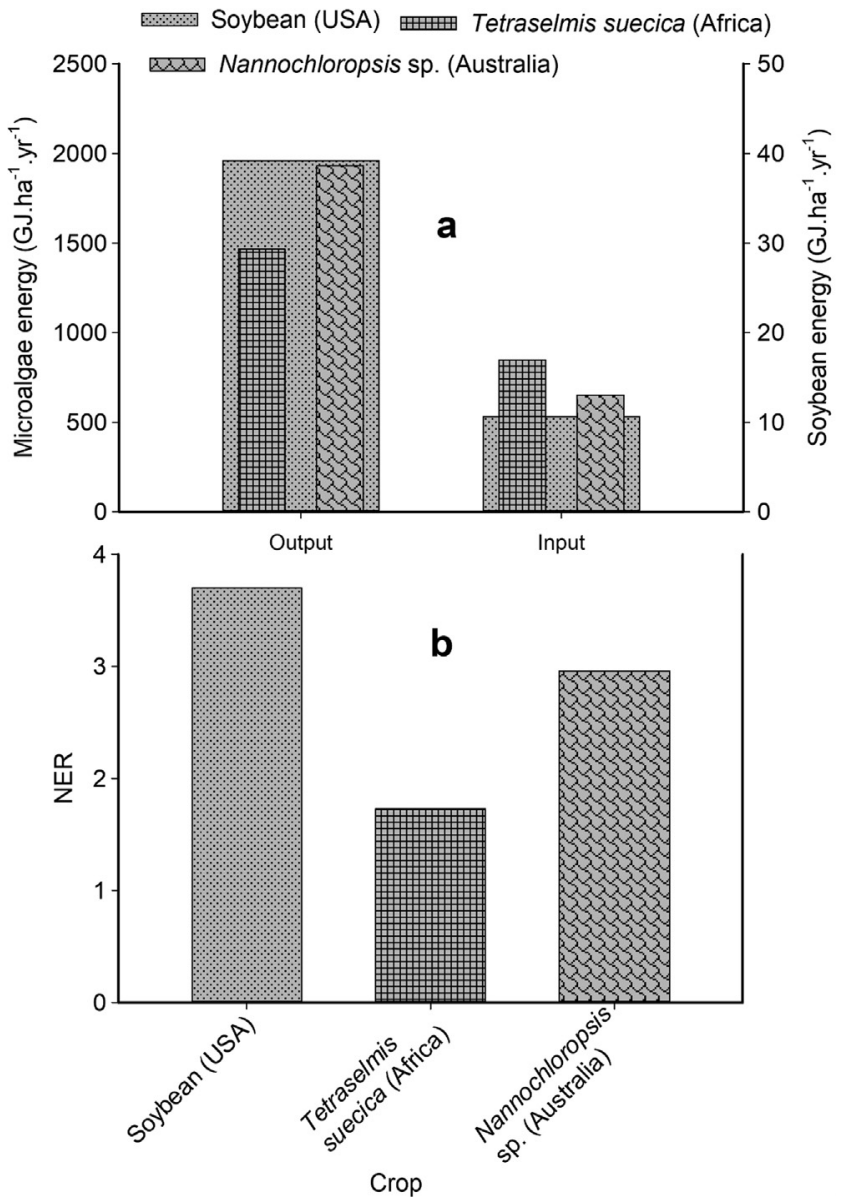

Fig. 4. (a) Annual energy output and input and, (b) NER for the production of soybean, Tetraselmis suecica, and Nannochloropsis sp. MUR 267 biomass in a 1ha plant. T. suecica and Nannochloropsis sp. plants are PV-integrated.

photobioreactor based microalgal plants [33]. However, this NER appears insufficient when compared to methods based on converting conventional crops as fuel, feed, or food sources, as the analysis of the energetic efficiency of the plant does not include downstream processing of the wet biomass (see system boundary, Fig. 1). Nonetheless, these results do show that the cultivation of microalgae in the IGP photobioreactor is energetically sustainable and can compete favorably with conventional food/biofuel crops considering the market value of the final product or a multi-product biorefinery scenario. For example, one of the most important crops in the world, soybean (Glycine max), has average annual grain productivity of 2.6 tons $\mathrm{ha}^{-1} \mathrm{yr}^{-1}$ (Fig. 4). This yield corresponds to energy output and input of 39.2 and $10.6 \mathrm{GJ}$ $\mathrm{ha}^{-1} \mathrm{yr}^{-1}$, respectively resulting in a high NER value of 3.7 [56], not that much higher than the 2.96 calculated for the IGP photobioreactor. The primary energy inputs included in the system boundary of soybean grain production were labor, machinery, fertilizers, electricity, herbicides, and transportation. For other microalgal studies with similar plant size and no PV intervention, variable NERs of 0.6-7.1 have been reported $[33,34]$

The use of microalgal photobioreactor based systems also has the potential to reduce the environmental impact of biofuel and biocommodity production as a result of the substantially higher concentration of lipids etc. present in microalgae compared to soil-based crops. For example, the lipid content of soybean is $18 \%$ dry weight [57] vs. $50-55 \%$ (based on ash-free dry weight) of Nannochloropsis MUR 267, [42] which converts to lipid yields of 0.47 tons $\mathrm{ha}^{-1} \mathrm{yr}^{-1}$ and 33.0-36.3 tons $\mathrm{ha}^{-1} \mathrm{yr}^{-1}$, respectively. Lipid yield of Nannochloropsis sp. in the IGP photobioreactor is 74 times higher than the soybean oil. A similar difference in yield is also seen for non-food bioenergy crops, such as Jatropha curcas, where the average dry seed yield and oil content is 5 tons $\mathrm{ha}^{-1} \mathrm{yr}^{-1}$ and $34.4 \%$, respectively [58]. That equates to a lipid yield for Jatropha crops of 1.72 tons $\mathrm{ha}^{-1} \mathrm{yr}^{-1}$, a value that is still 20 times less than that of Nannochloropsis sp. Even in a biorefinery scenario, e.g., the conjoint production of lipid and protein, the use of the IGP photobioreactor is comparable to soil-based cropping. The protein content of soybean is $35 \%$ [34] vs. 38-40\% for a Nannochloropsis sp. MUR 267 maintained at the logarithmic growth phase $[41,42,53]$, which translates to a calculated protein yield from nutrient replete Nannochloropsis sp. biomass of 25.1-26.4 tons ha ${ }^{-1} \mathrm{yr}^{-1}$, compared to a paltry 0.91 tons $\mathrm{ha}^{-1} \mathrm{yr}^{-1}$ for soybean. These results are not limited to Nannochloropsis as Tredici et al. [34] have reported comparable protein yields of Tetraselmis suecica ( $45 \%$ protein content) cultured in a GWP plant as 16 tons $\mathrm{ha}^{-1} \mathrm{yr}^{-1}$ in Tuscany (Italy) and 30 tons $\mathrm{ha}^{-1} \mathrm{yr}^{-1}$ in Tunisia (Africa). Overall, Nannochloropsis sp. biomass yield in the IGP photobioreactor per unit land area reaches 1696.2 GJ $\mathrm{ha}^{-1} \mathrm{yr}^{-1}$, leading to a net energy balance (gain) of $1279.2 \mathrm{GJ}^{\mathrm{ha}}{ }^{-1}$ $\mathrm{yr}^{-1}$ (Table 4), which is 45 times higher than that of soybean.

The environmental sustainability credentials of microalgal culture are often touted as being significantly greater than soil-based cropping, particularly as saline microalgal culture can conceivably be achieved in desert and arid zone areas with where cropping is marginal at best. However, Morales et al. [11] have recently reminded us that the actual long term environmental and financial viability of these facilities is based on a rigorous examination of both environmental, energy, and economic parameters. Thus the actual impact and viability of new technologies need to be assessed not only by energy analysis but the other tools available via life-cycle and rigorous techno-economic analysis. We are currently in the process of undertaking such analyses for an IGP based facility.

Other options for improving the NER of the integrated photobioreactor system can be explored through optimization of the microalgae cultivation process and optimizing the optical properties of the semi-transparent PV panel and its energy conversion efficiency. Improvement in the PV efficiency should mean higher electricity production for the same PV coverage, and thus, increasing the overall energy output of the plant. Combining the technology with strain selection, e.g., microalgal strains that are resistant to temperature fluctuation and with higher annual biomass productivity, would obviously improve viability. Photobioreactor design parameters can also be investigated in greater detail to better dissipate heat and/or increase thermal inertia to diel variation of culture temperature.

The net energy ratio analysis performed demonstrates that PV integration with microalgae production in photobioreactors is advantageous from an energy efficiency viewpoint. The incorporation of that PV capacity directly into the photobioreactor design only enhances the NER and results in a standalone cultivation system, that provides an excellent energy-efficient technology suitable for the production of high-quality microalgal feedstocks for aquaculture, value-added pigments, pharmaceuticals, nutraceuticals, and bioactive compounds. This photobioreactor provides a reliable experimental platform for studying microalgal performance on a large-scale, especially in remote areas lacking grid electricity and access to freshwater for evaporative cooling.

\section{Conclusions}

The integration of semi-transparent photovoltaic panels to spectrally-selective insulated glazed photobioreactors offers a trinity of benefits: (a) sourcing local electricity for the plant operation; (b) eliminating freshwater-based cooling of photobioreactors, and (c) a strong reduction in diel temperature fluctuation. These could neutralize the strong external cooling water and electrical energy requirements of microalgal photobioreactors. In this study, the primary energy inputs and outputs for an industrial 1-ha installation of insulated glazed photovoltaic (IGP) self-cooling photobioreactors for the production of 
Nannochloropsis sp. MUR 267 biomass have been investigated. Biomass productivity data for Nannochloropsis sp. cultivation in a pilot IGP photobioreactor was scaled to 1-ha and indicated the generation of 66.0 tons $\mathrm{ha}^{-1} \mathrm{yr}^{-1}$ of biomass and combined energy output (biomass + PV) of $1931 \mathrm{GJ}^{-1} \mathrm{yr}^{-1}$. Energy inputs to the plant added up to $652 \mathrm{GJ} \mathrm{ha}^{-1} \mathrm{yr}^{-1}$, of which $63 \%$ is contributed by the energy embodied in plant materials and $37 \%$ from fertilizers, culture mixing, and culture harvesting. The analysis indicated that an NER of 3.0 is achievable for the IGP photobioreactor. Comparable analysis for non-PV integrated photobioreactor requiring passive evaporative cooling provided an NER of only 0.8 . The calculated NER value for the IGP module is comparable to the best soil-based crops utilized for lipidbased oil production, indicating that this technology could be considered economically viable for mass production of Nannochloropsis biomass for various bio-based products. Results show that high net energy gain (1279 $\mathrm{GJ} \mathrm{ha}^{-1} \mathrm{yr}^{-1}$ ) and lipid yield that is at least 25 times higher than dedicated bioenergy crops such as Jatropha curcas, can be achieved, demonstrating the high potential of the IGP photobioreactor for the cultivation of microalgae for food, feed, biofuel, personal care, and pharmaceutical applications. The experimental and calculated results from the standalone IGP photobioreactor suggest that commercially sized installations based on the incorporation of spectral selection and integrated transparent PV should play a significant role in future scenarios for the scaling up of grid-independent production of biomass, bioproducts and renewable electricity from a single algal plant installation.

\section{CRediT authorship contribution statement}

Emeka G. Nwoba: Conceptualization, Methodology, Investigation, Formal analysis, Validation, Writing - original draft, Writing - review \& editing. David A. Parlevliet: Conceptualization, Formal analysis, Funding acquisition, Resources, Methodology, Validation, Supervision, Writing - review \& editing. Damian W. Laird: Conceptualization, Funding acquisition, Resources, Supervision, Writing - review \& editing. Kamal Alameh: Conceptualization, Funding acquisition, Resources, Methodology, Validation, Supervision, Writing - review \& editing. Julien Louveau: Formal analysis, Validation, Writing - review \& editing. Jeremy Pruvost: Formal analysis, Resources, Methodology, Validation, Writing - review \& editing. Navid R. Moheimani: Conceptualization, Funding acquisition, Resources, Methodology, Supervision, Writing - review \& editing.

\section{Declaration of competing interest}

The authors declare that they have no known competing financial interests or personal relationships that could have appeared to influence the work reported in this paper.

\section{Acknowledgements}

This work was financially supported by Murdoch University. The authors would like to thank Emeritus Prof. Michael Borowitzka for his intellectual advice.

\section{References}

[1] Chisti Y. Biodiesel from microalgae. Biotechnol Adv 2007;25:294-306.

[2] Zhu X-G, Long SP, Ort DR. What is the maximum efficiency with which photosynthesis can convert solar energy into biomass? Curr Opin Biotechnol 2008;19:153-9.

[3] Voloshin RA, Rodionova MV, Zharmukhamedov SK, Veziroglu TN, Allakhverdiev SI. Biofuel production from plant and algal biomass. Int J Hydrogen Energy 2016;41:17257-73.

[4] Ishika T, Moheimani NR, Bahri PA. Sustainable saline microalgae co-cultivation for biofuel production: A critical review. Renew. Sust. Energy Rev. 2017;78:356-68.

[5] Naaz F, Bhattacharya A, Pant KK, Malik A. Investigations on energy efficiency of biomethane/biocrude production from pilot scale wastewater grown algal biomass.
Appl Energy 2019;254:113656

[6] Li X, Yang C, Zeng G, Wu S, Lin Y, Zhou Q, et al. Nutrient removal from swine wastewater with growing microalgae at various zinc concentrations. Algal Res 2020;46:101804.

[7] Li X, Yang WL, He H, Wu S, Zhou Q, Yang C, et al. Responses of microalgae Coelastrella sp. to stress of cupric ions in treatment of anaerobically digested swine wastewater. Bioresour Technol 2018;251:274-9.

[8] Luo L, He H, Yang C, Wen S, Zeng G, Wu M, et al. Nutrient removal and lipid production by Coelastrella sp. in anaerobically and aerobically treated swine wastewater. Bioresour Technol 2016;216:135-41.

[9] Vadiveloo A, Nwoba EG, Ogbonna C, Mehta P. Sustainable production of bioproducts from wastewater-grown microalgae. Sustainable Downstream Processing of Microalgae for. Ind Appl 2019:165.

[10] Jez S, Spinelli D, Fierro A, Dibenedetto A, Aresta M, Busi E, et al. Comparative life cycle assessment study on environmental impact of oil production from micro-algae and terrestrial oilseed crops. Bioresour Technol 2017;239:266-75.

[11] Morales M, Hélias A, Bernard O. Optimal integration of microalgae production with photovoltaic panels: environmental impacts and energy balance. Biotechnol Biofuels 2019;12:239.

[12] Borowitzka MA. Commercial production of microalgae: ponds, tanks, tubes and fermenters. J Biotechnol 1999;70:313-21.

[13] Brennan L, Owende P. Biofuels from microalgae-a review of technologies for production, processing, and extractions of biofuels and co-products. Renew Sust Energy Rev 2010;14:557-77.

[14] Rawat I, Kumar RR, Mutanda T, Bux F. Biodiesel from microalgae: a critical evaluation from laboratory to large scale production. Appl Energy 2013;103:444-67.

[15] Singh A, Nigam PS, Murphy JD. Mechanism and challenges in commercialisation of algal biofuels. Bioresour Technol 2011;102:26-34.

[16] Pruvost J, Goetz V, Artu A, Das P, Al Jabri H. Thermal modeling and optimization of microalgal biomass production in the harsh desert conditions of State of Qatar. Algal Res 2019;38:101381.

[17] Goetz V, Le Borgne F, Pruvost J, Plantard G, Legrand J. A generic temperature model for solar photobioreactors. Chem Eng J 2011;175:443-9.

[18] Pruvost J, Le Gouic B, Lepine O, Legrand J, Le Borgne F. Microalgae culture in building-integrated photobioreactors: Biomass production modelling and energetic analysis. Chem Eng J 2016;284:850-61.

[19] Torzillo G, Sacchi A, Materassi R, Richmond A. Effect of temperature on yield and night biomass loss in Spirulina platensis grown outdoor in tubular photobioreactor. J Appl Phycol 1991;3:103-9.

[20] Moheimani NR, Parlevliet D. Sustainable solar energy conversion to chemical and electrical energy. Renew Sust Energy Rev 2013;27:494-504.

[21] Nwoba EG, Parlevliet DA, Laird DW, Alameh K, Moheimani NR. Sustainable phycocyanin production from Arthrospira platensis using solar-control thin film coated photobioreactor. Biochem Eng J 2019;141:232-8.

[22] Nwoba EG, Parlevliet DA, Laird DW, Alameh K, Moheimani NR. Pilot-scale selfcooling microalgal closed photobioreactor for biomass production and electricity generation. Algal Res. 2020;45:101731.

[23] Jorquera O, Kiperstok A, Sales EA, Embirucu M, Ghirardi ML. Comparative energy life-cycle analyses of microalgal biomass production in open ponds and photobioreactors. Bioresour Technol 2010;101:1406-13.

[24] Burgess G, Fernández-Velasco JG. Materials, operational energy inputs, and net energy ratio for photobiological hydrogen production. Int J Hydrogen Energy 2007;32:1225-34.

[25] Beal CM, Hebner RE, Webber ME, Ruoff RS, Seibert AF, King CW. Comprehensive evaluation of algal biofuel production: experimental and target results. Energies. 2012;5:1943-81.

[26] Wijffels RH, Barbosa MJ. An outlook on microalgal biofuels. Science 2010;329:796-9.

[27] Razon LF, Tan RR. Net energy analysis of the production of biodiesel and biogas from the microalgae: Haematococcus pluvialis and Nannochloropsis. Appl Energy 2011;88:3507-14.

[28] Hoffman J, Pate RC, Drennen T, Quinn JC. Techno-economic assessment of open microalgae production systems. Algal Res 2017;23:51-7.

[29] Quinn JC, Davis R. The potentials and challenges of algae based biofuels: a review of the techno-economic, life cycle, and resource assessment modeling. Bioresour Technol 2015;184:444-52.

[30] DeRose K, DeMill C, Davis RW, Quinn JC. Integrated techno economic and life cycle assessment of the conversion of high productivity, low lipid algae to renewable fuels. Algal Res 2019;38:101412.

[31] Jones M, Odeh I, Haddad M, Mohammad A, Quinn J. Economic analysis of photovoltaic (PV) powered water pumping and desalination without energy storage for agriculture. Desalination 2016;387:35-45.

[32] Vasudevan V, Stratton RW, Pearlson MN, Jersey GR, Beyene AG, Weissman JC, et al. Environmental performance of algal biofuel technology options. Environ Sci Technol 2012;46:2451-9.

[33] Hulatt CJ, Thomas DN. Productivity, carbon dioxide uptake and net energy return of microalgal bubble column photobioreactors. Bioresour Technol 2011;102:5775-87.

[34] Tredici M, Bassi N, Prussi M, Biondi N, Rodolfi L, Zittelli GC, et al. Energy balance of algal biomass production in a 1-ha "Green Wall Panel" plant: how to produce algal biomass in a closed reactor achieving a high net energy ratio. Appl Energy 2015;154:1103-11.

[35] Boruff BJ, Moheimani NR, Borowitzka MA. Identifying locations for large-scale microalgae cultivation in Western Australia: A GIS approach. Appl Energy 2015;149:379-91.

[36] Nwoba EG, Parlevliet DA, Laird DW, Alameh K, Moheimani NR. Light management 
technologies for increasing algal photobioreactor efficiency. Algal Res 2019;39:101433.

[37] Raes E, Isdepsky A, Muylaert K, Borowitzka M, Moheimani N. Comparison of growth of Tetraselmis in a tubular photobioreactor (Biocoil) and a raceway pond. J Appl Phycol 2014;26:247-55.

[38] Nwoba EG, Ayre JM, Moheimani NR, Ubi BE, Ogbonna JC. Growth comparison of microalgae in tubular photobioreactor and open pond for treating anaerobic digestion piggery effluent. Algal Res 2016;17:268-76.

[39] Reyna-Velarde R, Cristiani-Urbina E, Hernández-Melchor DJ, Thalasso F, CañizaresVillanueva RO. Hydrodynamic and mass transfer characterization of a flat-panel airlift photobioreactor with high light path. Chem Eng Process Process Intensif 2010;49:97-103.

[40] Hernández-Melchor DJ, Cañizares-Villanueva RO, Terán-Toledo JR, López-Pérez PA, Cristiani-Urbina E. Hydrodynamic and mass transfer characterization of flatpanel airlift photobioreactors for the cultivation of a photosynthetic microbial consortium. Biochem Eng J 2017;128:141-8.

[41] Vadiveloo A, Moheimani N, Alghamedi R, Cosgrove JJ, Alameh K, Parlevliet D. Sustainable cultivation of microalgae by an insulated glazed glass plate photobioreactor. Biotechnol J 2015;363-74.

[42] Nwoba EG, Parlevliet DA, Laird DW, Vadiveloo A, Alameh K, Moheimani NR. Can solar control infrared blocking films be used to replace evaporative cooling for growth of Nannochloropsis sp. in plate photobioreactors? Algal Res 2019;39:101441.

[43] Vadiveloo A, Moheimani NR, Cosgrove JJ, Bahri PA, Parlevliet D. Effect of different light spectra on the growth and productivity of acclimated Nannochloropsis sp (Eustigmatophyceae). Algal Res 2015;8:121-7.

[44] Guillard RR, Ryther JH. Studies of marine planktonic diatoms: I. Cyclotella nana Hustedt, and Detonula confervacea (Cleve) Gran. Can J Microbiol 1962;8:229-39.

[45] Hammond GP, Jones CI. Embodied energy and carbon in construction materials. Proc Inst Civ Eng-Energy 2008;161:87-98.

[46] Andrew A. Embodied energy and $\mathrm{CO} 2$ coefficients for NZ building materials. Centre for Building Performance Research Report; 2003.

[47] Qarout L. Reducing the Environmental Impacts of Building Materials: Embodied Energy Analysis of a High-performance Building; 2017.

[48] Hammond G, Jones C, Lowrie F, Tse P. Inventory of carbon \& energy: ICE: Sustainable Energy Research Team, Department of Mechanical Engineering; 2008.

[49] Börjesson P. Energy analysis of biomass production and transportation. Biomass Bioenergy 1996;11:305-18.

[50] Tibbetts SM, Milley JE, Lall SP. Chemical composition and nutritional properties of freshwater and marine microalgal biomass cultured in photobioreactors. J Appl Phycol 2015;27:1109-19.

[51] Chisti MY. Airlift bioreactors. Elsevier Appl Sci London 1989.

[52] Moheimani N. Tetraselmis suecica culture for $\mathrm{CO}_{2}$ bioremediation of untreated flue gas from a coal-fired power station. J Appl Phycol 2016;28:2139-46.

[53] Vadiveloo A, Moheimani N. Effect of continuous and daytime mixing on Nannochloropsis growth in raceway ponds. Algal Res 2018;33:190-6.

[54] Sforza E, Barbera E, Bertucco A. Improving the photoconversion efficiency: An integrated photovoltaic-photobioreactor system for microalgal cultivation. Algal Res. 2015;10:202-9.

[55] Barbera E, Sforza E, Vecchiato L, Bertucco A. Energy and economic analysis of microalgae cultivation in a photovoltaic-assisted greenhouse: Scenedesmus obliquus as a case study. Energy. 2017;140:116-24.

[56] Pimentel D, Doughty R, Carothers C, Lamberson S, Bora N, Lee K. Energy inputs in crop production in developing and developed countries. Food Security Environ Quality Dev World 2002:129-51.

[57] Batan L, Quinn J, Willson B, Bradley T. Net energy and greenhouse gas emission evaluation of biodiesel derived from microalgae. Environ Sci Technol 2010;44:7975-80.

[58] Achten WM, Verchot L, Franken YJ, Mathijs E, Singh VP, Aerts R, et al. Jatropha bio-diesel production and use. Biomass Bioenergy 2008;32:1063-84. 